Revista de Derecho

de la Pontificia Universidad Católica de Valparaíso XXXIII (Valparaíso, Chile, $2^{\text {do }}$ Semestre de 2009)

[pp. 215 - 228]

\title{
TUTELA LABORAL DE DERECHOS FUNDAMENTALES Y CARGA DE LA PRUEBA
}

["Labor Guardianship of Fundamental Rights and the Proof"]

\author{
José Luis Ugarte Cataldo* \\ Universidad Diego Portales, Santiago de Chile
}

\begin{abstract}
RESUMEN
La nueva justicia laboral implementada por la ley $\mathrm{N}^{\circ} 20.087$ contempla la denominada acción de tutela laboral cuya finalidad central es la protección de los derechos fundamentales del trabajador de naturaleza no laboral, tales como la intimidad, la libertad de expresión o la honra. En las reglas previstas para dicha acción se contempla, por primera vez en Chile, una especial regla legal que alivia el esfuerzo probatorio de la víctima -el trabajador- de la conducta lesiva del empleador. Dicha regla legal altera, como se explica en este artículo, la carga material de la prueba, esto es, quien debe soportar el costo del hecho que no ha quedado suficientemente acreditado en el proceso.
\end{abstract}

\begin{abstract}
The labor justice implemented by law No. 20.087, contemplates the so-called action of labor guardianship, central aim of which is the protection of the fundamental non-labor related rights of the worker, such as privacy, freedom of speech or the honor. Among the rules stated for said action, there is a legal rule that alleviates the probatory effort of the victim -the worker- from the injurious behavior of the employer. As this article explains, said legal rules changes the material burden of the proof. In other words, who has to bear the cost that has not been sufficiently proven in the proceedings.
\end{abstract}

* Profesor e Investigador de Derecho del Trabajo. Universidad Diego Portales. Dirección Postal: Avenida República 105, Santiago. Dirección Electrónica: jose. ugarte@udp.cl 
Palabras clave: Tutela laboral Derechos fundamentales del trabajador - Prueba de indicios - Carga material de la prueba - Despido pluricausal.
KEYWORDS Labor guardianship - Fundamental rights of the worker Evidence proof - Material burden of the proof - Pluricausal sacking.

\section{LA JUSTIFICACIÓN DE UNA REGLA ESPECIAL DE PRUEBA EN LA TUTELA LABORAL DE DERECHOS FUNDAMENTALES}

La reforma procesal laboral implementada por la Ley $\mathrm{N}^{\circ} 20.087$ (DO. de 3 de enero de 2006) y en particular el procedimiento de tutela, es el primer paso del orden jurídico laboral por tomar en serio los denominados derechos fundamentales inespecíficos de los trabajadores - derechos constitucionales no propiamente laborales-, comenzando poco a poco a desmontarse lo que podríamos denominar el modelo cerrado de empresa, entendido como un espacio jurídico privado donde la acción de los derechos sólo quedaba restringida al cumplimiento de condiciones laborales y económicas mínimas, para dar paso a un espacio jurídico público, expuesto al efecto expansivo de los derechos fundamentales. Idea esta última, a la que por fin, comienza a confluir tanto la ley como la jurisprudencia judicial.

El procedimiento de tutela de derechos fundamentales va, precisamente, en esta dirección y supera en buena medidas las insuficiencias que recién señalamos hicieron imposible que el recurso de protección sirviera de algo en la protección de estos derechos. En efectos, la acción de tutela protege prácticamente casi todos los derechos constitucionales del trabajador, considera la posición débil del trabajador en el proceso propiamente tal, especialmente en la sensible cuestión de la valoración probatoria, y establece como consecuencia jurídica la nulidad de la conducta empresarial lesiva y en su defecto el pago indemnizatorio correspondiente ${ }^{1}$.

El marco en que se desenvolverá esta nueva acción queda delimitado por el artículo 485 C.Trab. que señala: "El procedimiento contenido en este Párrafo se aplicará respecto de las cuestiones suscitadas en la relación laboral por aplicación de las normas laborales, que afecten los derechos fundamentales de los trabajadores, entendiéndose por éstos los consagrados en la Constitución Política de la República en su artículo 19, números $1^{\circ}$, inciso primero, siempre que su vulneración sea consecuencia directa de actos ocurridos en la relación laboral, $4^{\circ}, 5^{\circ}$, en lo relativo a la inviolabilidad de toda forma de comunicación privada, $6^{\circ}$, inciso primero, $12^{\circ}$, inciso primero, y $16^{\circ}$, en lo relativo

\footnotetext{
${ }^{1}$ Respecto del procedimiento véase: GAMONAL, Sergio, El procedimiento de tutela de derechos laborales (2a edición, Santiago, LegalPublishing, 2008).
} 
a la libertad de trabajo, al derecho a su libre elección y a lo establecido en su inciso cuarto, cuando aquellos derechos resulten lesionados en el ejercicio de las facultades del empleador".

Ahora, es harto obvio que si, echando manos a esta nueva acción de tutela, un trabajador pretende demandar a su empleador porque entiende que ha sido despedido, por ejemplo, por su tendencia sexual o política, tiene un problema difícil de solucionar: cómo enfrentar el escenario de un despido que se encubrirá, la mayor de las veces, en la causal de necesidades de la empresa prevista en el artículo 161 C.Trab..

¿Cómo acreditar que el móvil del despido fue la consideración de la opción sexual o política del trabajador, y no la genérica y ambigua causal en que consiste en Chile las necesidades de la empresa, prevista como causal de término del contrato de trabajo en la ley laboral?

En el derecho comparado existe ya una idea consolidada sobre el difícil escenario probatorio que el trabajador debe enfrentar en las denuncias por violación o lesión de derechos fundamentales. Se hace, en consecuencia, imperativo para otorgar una tutela efectiva de dichos derechos, la reducción del esfuerzo probatorio en los procesos respectivos.

Las razones de la rebaja en el esfuerzo probatorio son básicamente dos:

Por una parte, el carácter manifiestamente hundido de las conductas lesivas de derechos fundamentales, las que se suelen encubrir en conductas aparentemente lícitas y no lesivas, lo que hace sino imposible, muy difícil la acreditación del móvil o de la finalidad discriminatoria o lesiva de derechos fundamentales. Como se ha destacado en la doctrina comparada, dichas conductas "nunca se presentarán como tales, salvo supuesto extremos, sino enmascaradas y ocultas".

Por otro lado, el entorno probatorio hostil que enfrenta el trabajador que demanda tutela de sus derechos fundamentales. En efecto, como se ha destacado ampliamente en la doctrina, "sobre la base de la constatación de un mayor poder del empresario sobre la prueba, derivado de su acusada proximidad y dominio sobre las fuentes probatorias, que desnivela profundamente las facilidades de una y otra respecto de la prueba de los hechos que avalan la pretensión del trabajador, la norma procesal laboral corrige las reglas sobre la carga de la prueba en el juicio"3.

${ }^{2}$ Garcia-Perrote, Ignacio, Prueba y proceso laboral, en Derecho Privado y Constitución 4 (1994), pp. 163-222.

${ }^{3}$ BAYLos, Antonio, La igualdad de las partes en el proceso laboral y la tutela judicial efectiva, en Revista del Colegio de Abogados de Concepción 5 (1998), p. 46. En el mismo sentido, CAAMAÑo, Eduardo, La defensa del principio de no discriminación por razones de sexo en el periodo anterior al nacimiento de la relación laboral, en Revista 
De este modo, para tomar la protección de los derechos fundamentales del trabajador en serio, se hace necesario el establecimiento de reglas especiales sobre el esfuerzo en la prueba de dichas conductas por "una pluralidad de razones interrelacionadas de política jurídica: la realización de intereses generales de justiciabilidad de los derechos fundamentales -garantías de justicia-; afrontar el problema práctico consistente en las dificultades de la prueba del hecho discriminatorio o contrario al derecho fundamental -debilidad de la posición probatoria", lo que lleva a establecer "reglas especiales de distribución de la prueba a favor de la posición subjetiva del trabajador, agravándose simétricamente la del empresario demandado"4.

Pero ¿en qué consiste la mencionada aliviación o rebaja probatoria en las denuncias por lesión de derechos fundamentales?

No existe sólo una técnica de aligeramiento probatorio, sino varias modalidades distintas que, sin embargo, sirven a un mismo objetivo: facilitar la posición probatoria por la vía de aligerar el esfuerzo probatorio del trabajador denunciante, atemperando, en algunos casos, los efectos del axioma central en la materia de que corresponde probar un hecho a quien lo alega (carga de la prueba formal), o modificando, en otros, el hecho de que el costo por la falta de certeza plena en la acreditación de un hecho debe soportarlo aquel que lo afirma (carga de la prueba material).

Y el derecho comparado ha actuado en consecuencia ${ }^{5}$. La Directiva $\mathrm{N}^{\circ}$ 97/80 de 1997 de la Unión Europea marcó un relevante hito en la materia, y en su artículo 4, a propósito de la carga de la prueba, señala que: "Los

Laboral Chilena 116 (2003); y UGarte, José Luis, El Nuevo Derecho del Trabajo (1a edición, Santiago, Editorial Universitaria, 2004), pp. 113 ss.

${ }^{4}$ Monereo, José Luis, La carga de la prueba en los despidos lesivos de derechos fundamentales (1 $1^{\text {a }}$ edición, Valencia, Tirant lo Blanch, 1996), p. 32.

${ }^{5}$ En el caso de España, primero a través de una famosa sentencia del Tribunal Constitucional sobre despido antisindical (STC No 38/1981), y después, por la vía de una norma legal expresa, se consagra una regla procesal sobre la carga de la prueba que tiene por objeto hacer más liviano para la víctima el esfuerzo probatorio en los procesos por lesión de derechos fundamentales. Dicho precepto, el artículo 179.2 de la Ley de procedimiento laboral (LPL.), señala que "en el acto del juicio constatada la concurrencia de indicios de que se ha producido violación de la libertad sindical (o de otro derecho fundamental), corresponderá al demandado la aportación de una justificación objetiva y razonable, suficientemente probada, de las medidas adoptadas y su proporcionalidad'. En Alemania, el parágrafo 611 a inciso 1 frase 3 BGB. señala que en caso de que el trabajador logre acreditar hechos que permiten presumir la existencia de un trato no igualitario en razón del sexo, le corresponde al empleador asumir la carga de probar que el trato no igualitario se encuentra justificado por razones objetivas que dicen relación con el sexo, o bien, probar que la consideración al sexo del trabajador es un requisito imprescindible en la actividad a ser desarrollada. Ver CaAmaño, Eduardo, cit. (n. 2), p. 232. 
Estados miembros adoptarán con arreglo a sus sistemas judiciales nacionales las medidas necesarias para que, cuando una persona que se considere perjudicada por la no aplicación, en lo que a ella se refiere, del principio de igualdad de trato presente, ante un órgano jurisdiccional u otro órgano competente, hechos que permitan presumir la existencia de discriminación directa o indirecta, corresponda a la parte demandada demostrar que no ha habido vulneración del principio de igualdad de trato".

El derecho laboral chileno pretende seguir el mismo camino. Para ello, se introduce una norma completamente novedosa para la regulación procesal en nuestro país: "cuando de los antecedentes aportados por la parte denunciante resulten indicios suficientes de que se ha producido la vulneración de derechos fundamentales, corresponderá al denunciado explicar los fundamentos de las medidas adoptadas y de su proporcionalidad" (artículo 493 C.Trab.).

En este punto es importante determinar tres cuestiones: i) qué tipo de aligeramiento o reducción de la prueba es la que establece esta norma, ii) cómo se accede a esta reducción o, dicho en otras palabras, qué es lo que debe probar el trabajador, y iii) en qué escenario queda el empleador afectado por la reducción probatoria del nuevo precepto legal citado.

\section{LA TÉCNICA DE INDICIOS: LA ALTERACIÓN DE LA CARGA MATERIAL DE LA PRUEBA}

1. Respecto de la naturaleza de la reducción probatoria establecida en el artículo 493 C.Trab., cabe señalar que no se trataría de un riguroso caso de inversión de la carga formal de la prueba (onus probandi). En efecto, no es suficiente que se alegue una lesión de derechos fundamentales para que se traslade al empleador la carga probatoria, y por ello, en rigor, a pesar de la confusión de algunos, no se altera el axioma de que corresponde probar un hecho al que lo alega fundado en lo dispuesto en el artículo 1698 CC.: "incumbe probar las obligaciones o su extinción al que alega aquéllas o ésta".

Se trata, en rigor, de una técnica más débil. La víctima o denunciante no está completamente liberado de prueba: debe acreditar la existencia de indicios suficientes de la existencia de la conducta lesiva, para que en ese caso, y sólo en ese caso, podrá aprovecharse el trabajador de la regla prevista en el artículo 493 C.Trab., en virtud de la cual corresponde al demandado el deber de probar que su conducta se debió a motivos objetivos y razonables ${ }^{6}$.

${ }^{6}$ Frente a una norma similar, y pese a vacilaciones iniciales, la doctrina española ha concluido que "no estamos ante una auténtica inversión de la carga de la prueba 
En ese sentido, la actividad probatoria de las partes en el procedimiento de tutela no tiene variaciones formales respecto de otros procedimientos laborales. Dicho de otro modo, el sistema probatorio de este tipo de asuntos es exactamente el mismo que en el resto de los conflictos jurídicos laborales. En ese sentido, las reglas sobre la carga formal de la prueba (quién debe probar) y los medios de prueba (cómo se debe probar) son las mismas que las previstas para el procedimiento de aplicación general.

2. Pero, entonces ¿en qué consiste la regla del artículo 493 C.Trab.?7 La respuesta supone varios aspectos por considerar:

a) Es una regla que altera o modifica, en razón de dar tutela efectiva a los derechos fundamentales del trabajador, la denominada carga material de la prueba, esto es, la distribución del costo del hecho que ha quedado inciertamente determinado por los medios de fijación o de prueba que han operado en la etapa probatoria del procedimiento de tutela.

En ese sentido, la carga material de la prueba "despliega su eficacia cuando en el litigio no ha quedado acreditado algún hecho relevante, de tal forma que si los hechos permanecen inciertos o dudosos, se habrán de desestimar las pretensiones de la parte a quien correspondía" su acreditación probatoria ${ }^{8}$. De este modo, como ha afirmado la doctrina, que la "regulación de la carga de la prueba va dirigida únicamente al órgano judicial,

en sentido técnico jurídico porque al demandante le corresponde la carga de realizar alguna actividad probatoria, sino de una distribución de la carga de la prueba entre los litigantes diferente a la derivada de la estricta aplicación de las normas procesales generales", LOUSADA, José Fernando, La jurisprudencia constitucional sobre la prueba de la discriminación, en Revista Derecho Social 30 (2005), p. 38. Cuestión que ha sido precisada, incluso, por el propio Tribunal Constitucional español: "lo que en puridad existe es una reducción de la carga probatoria, puesto que el que alega la discriminación deberá probar hechos que permitan deducir al menos indicios de esa discriminación, que permitan deducir realmente que está en juego el principio de igualdad, lo que supondría al empresario desarrollar una actividad probatoria para destruir esa presunción" (STC No 21/1992).

${ }^{7}$ La naturaleza institucional de esta norma de alivio probatorio es discutida: así para algunos se trata de una presunción legal, como GASCON, Mariana, Los hechos en el Derecho ( $1^{\text {a }}$ edición, Madrid, Marcial Pons, 1999), p. 139. Para otros, en cambio, se trata de un principio de prueba, como ocurre con Garcia-Perrote, Ignacio, La prueba en el proceso de trabajo (1 $1^{\text {a }}$ edición, Madrid, Civitas, 1994), p. 210. Para otros, en rigor, es una regla de valoración jurídica, como sostiene SANCHEZURÁN, Yolanda, Despido y móvil discriminatorio, en Actualidad Laboral 14 (2007), p. 1.679 .

${ }^{8}$ Fraga, Enrique Juanes, La prueba en el proceso de trabajo: novedades de la ley de Enjuiciamiento Civil, en VV. AA., El proceso laboral (Valladolid, Lex Nova, 2001), p. 384. 
para ser aplicada por él cuando a la hora de confeccionar la sentencia, y a pesar de haberse practicado uno o varios medios de prueba sobre uno o varios hechos, tenga dudas de la certeza de los mismos. Es decir, la carga de la prueba sólo opera en la fase de la redacción de la resolución judicial"”.

Precisamente, en tutela laboral, esa alteración modifica la respuesta a la pregunta de quién debe soportar el sacrificio del hecho que no ha quedado suficientemente probado en el juicio, pero sobre el cual recae una razonable sospecha de su ocurrencia.

Y explicada así, la regla del 493 C.Trab., no corresponde en sentido estricto a una regla de la etapa probatoria, sino a una regla de juicio, esto es, una regla que opera cuando el juez, al momento de dictar la sentencia, debe resolver quién debe soportar el costo del hecho que en el proceso no ha quedado plenamente acreditado, pero de cuya ocurrencia, por la presencia de indicios al respecto, se guarda razonable duda.

En este caso, el hecho cuya razonable duda queda en el proceso- que no es sino el hecho de haber ocurrido la conducta lesiva de derechos fundamentales-afectará, a diferencia de la pauta distributiva normal de un proceso judicial, al demandado, quien sabe desde el inicio del proceso que en la acción de tutela existe, por expresa disposición legal, una distribución alterada de la carga material del costo probatorio ${ }^{10}$.

\footnotetext{
${ }^{9}$ GIL, Juan, La carga de la prueba en el proceso laboral tras la LECiv 1/2000, en Revista Española de Derecho del Trabajo 126 (2005), p. 91.

${ }^{10} \mathrm{La}$ acreditación de una discriminación o una lesión de derechos fundamentales sin una regla de alivio probatorio, es casi imposible y equivale en algún sentido a no tomarse en serio la protección de esos derechos. Sometidos a la distribución normal de la carga probatoria material propias de los procesos civiles, accionar para proteger esos derechos es perder el tiempo. Así lo demuestra, por ejemplo, un reciente recurso de protección a favor del comerciante Michael Espinoza en contra del alcalde de Independencia Antonio Garrido Mardones, quien habría negado el permiso de comercio ambulante por la opción sexual del primero -de transexualidad-, y acreditado en el proceso que el citado alcalde declaró a la prensa, "si quiero le doy permiso al mariconcito" (Diario La Cuarta, 7 de Junio del 2008), "No tengo problemas con los gays, pero gracias a Dios ninguno de mis hijos lo es", "venis a hacer polémica, jcorrete no más!" y "ya po, anda el lunes, pero te cortai el pelo y vai vestido con buzo, asi podis trabajar" (Diario Las Ultimas Noticias, 8 de Junio del 2008). La Corte de Apelaciones de Santiago, que niega la protección solicitada, muestra en este caso la inutilidad patente de normas antidiscriminatorias sin reglas de alivio probatorio: parte sosteniendo, ante tanto indicios acreditados en el proceso, que "lo manifestado por el recurrente aparece revestido de sustento fáctico, sólo en cuanto a que la prensa ha atribuido al Alcalde algunas expresiones que atacarian su opción sexual', pero que habría sido necesario "antecedentes concretos que permitirían a esta Corte establecer de manera irrefutable" la discriminación, y considera que el recurso aparece desprovisto de los antecedentes plausibles que lo hagan sustentable como acción constitucional
} 
b) En ese sentido, se trata de una regla legal de juicio que no opera, por tanto, ni en la etapa de aceptabilidad de la prueba -audiencia preparatoriani de la rendición o incorporación de la prueba-audiencia de juicio- sino que en la etapa de la construcción de la sentencia por parte del juez, esto es, en el de la decisión judicial del fondo del asunto.

De este modo, es perfectamente posible que no sea necesario aplicar la regla de juicio contenida en el artículo 493 C.Trab. Más precisamente, en dos casos opuestos: i) el trabajador logró la prueba del hecho lesivo mediante la aportación de prueba directa sobre el hecho; o ii) el empleador logró acreditar hechos constitutivos de una justificación objetiva y proporcionada de la conducta.

En estos casos, el hecho de la conducta lesiva no se encuentra incierta o dudosa, sino todo lo contrario: hay certeza probatoria de que ella ocurrió o de que, por el contrario, no es efectiva. En el medio se encuentra la situación que da operatividad a la regla legal de distribución de sacrificio probatorio del 493 C.Trab.: que el hecho de la conducta lesiva haya quedado, mediante los indicios exigidos, inciertamente acreditado. En dicho caso, y ante ausencia de prueba del empleador que destruya la incertidumbre, el costo del hecho incierto o dudoso debe ser soportado por el demandado.

Como es fácil de advertir, si esta es una regla legal de juicio, entonces, se entiende conocida por las partes del proceso, tal como las partes, sin necesidad que nadie se lo aclare al momento de iniciar el litigio, saben de la regla del 1698 CC. que establece la carga formal de la prueba en los procesos judiciales ${ }^{11}$. En rigor, las partes del proceso saben o deben saber, bajo la regla de presunción de conocimiento del derecho del artículo 8 CC., que en el proceso de tutela, la carga material de distribución de la prueba se encuentra alterada, y que el hecho de la conducta lesiva quede bajo la razonable sospecha de su ocurrencia, provocada por el panorama indiciario presentado por el trabajador y ante la falta de actividad probatoria del empleador que lo destruya, deberá ser soportado por el demandado.

No se trata, en fin, de una presunción judicial - que nazca por decisión del juez de la causa-sino una regla legal de distribución del costo o sacrificio

(Sentencia de la Corte de Apelaciones de Santiago, de fecha 18 de noviembre de 2008, rol No 4393-2008).

${ }^{11}$ En ese sentido, son absurdas y no entienden la naturaleza de la regla en comento, las críticas dirigidas a que el empleador se entera de modo sorpresivo, sólo en la audiencia de juicio, que el trabajador se piensa valer de la regla de indicios. Asimismo, y en sentido contrario, aunque parezca torpe aclararlo, el demandante sabe que fuera de este proceso de tutela, si el hecho fundante del cual depende su demanda, queda en la duda o en la sospecha de su ocurrencia, deberá soportar el costo o sacrificio probatorio respectivo. 
probatorio, que como tal debe entenderse conocida por las partes, como cualquier otra regla de derecho.

\section{LOS INDICIOS PROBATORIOS DE LA CONDUCTA LESIVA Y LA PRUEBA DEL EMPLEADOR.}

En segundo lugar, en lo referido al acceso a esta reducción probatoria para el trabajador, cabe señalar que para que el denunciante se aproveche de esta ventaja procesal, le corresponde acreditar la existencia de indicios suficientes de que se ha producido la vulneración de los derechos fundamentales protegidos por el procedimiento.

¿A qué tipos de indicios suficientes se refiere la ley?

Dichos indicios dicen relación con "hechos que han de generar en el juzgador al menos la sospecha fundada de que ha existido lesión de derechos fundamentales". Por ello, la prueba reducida de que se beneficia el trabajador se traduce en la prueba de hechos que generen en el juez una sospecha razonable de que ha existido la conducta lesiva ${ }^{12}$.

No cabe hacer aquí muchas apreciaciones adicionales, ya que la prueba de indicios no es nada novedosa en el derecho en general: corresponde a lo que se denomina prueba indirecta o circunstancial, que se caracteriza, a diferencia de la prueba directa, "en que no versa directamente sobre el hecho principal que se pretende probar y del que depende la decisión judicial". No hay, como ha apuntado la doctrina procesal moderna, otra diferencia relevante entre prueba directa e indirecta que el objeto de la prueba, y en ningún caso, presentan diferencias estructurales desde el punto de vista de la calidad epistemológica de las mismas ${ }^{13}$.

${ }^{12}$ Martínez Rocamora, Luis, Decisiones empresariales y principio de igualdad (1 ${ }^{\text {a }}$ edición, Barcelona, Cedecs, 1998), p. 174.

${ }^{13}$ En ese sentido, se ha afirmado que "parece que la espontaneidad en un caso (prueba directa) y la necesidad de razonar en el otro (prueba indirecta) conlleva también una diferente calidad epistemológica (y por tanto un diferente valor o fuerza probatoria) de sus resultados: mayor en el primer caso, "por ser en cierto modo tarea más teñida de objetividad y por tanto de imparcialidad"; menor en el segundo, porque "hace entrada en ella la subjetividad del juez en cuanto, mentalmente, ha de realizar el engarce entre el hecho base y el hecho consecuencia”. Esta distinción, sin embargo, no parece aceptable, pues se funda en una acrítica percepción de la llamada prueba directa. Analizada rigurosamente, la declaración del testigo Ta: "vi a A disparar a B y a éste caer muerto", ejemplo de prueba directa, no prueba por sí sola (directa y espontáneamente, sin necesidad de raciocinio) el hecho que se pretende probar (que A mató a B); lo único que esta declaración prueba por sí sola es que "el testigo Ta dice que vio a A disparar a B y a éste caer muerto". La declaración de Ta probará que "A mató a B" sólo si Ta dice la verdad (es decir, si no miente, ni sufrió un error de percepción, ni ahora sufre errores de la memoria); pero este dato (que Ta dice la verdad) es el resultado de una 
Se trata, en rigor, de lo que técnicamente se denomina principio de prueba. El trabajador debe aportar indicios que no prueben inmediata y directamente el hecho principal -la conducta lesiva- sino que, cosa distinta, hechos o circunstancias que logren generar en el juez laboral la sospecha razonable de que esa conducta lesiva denunciada se ha producido.

Tal como lo ha señalado la jurisprudencia comparada en caso de una regla probatoria similar: "un indicio razonable de que tal lesión se ha producido, vale decir, un principio de prueba dirigido a poner de manifiesto, en su caso, el motivo oculto de aquel acto" ${ }^{\prime 1}$.

Los indicios en esta materia pueden ser, entre otros: i) la correlación temporal del ejercicio del derecho fundamental y la conducta lesiva del empleador (como ocurriría si una vez enterado el empleador que el trabajador ha efectuado una denuncia lo despidiera en el tiempo inmediato); ii) manifestaciones del empleador que den a entender o puedan leerse motivadas por un móvil lesivo de derechos fundamentales; iii) la comparación del trato del empleador a trabajadores en una situación comparable al denunciante, y especialmente iv) la existencia de un clima lesivo de derechos fundamentales de la empresa dado por conductas previas y persistentes del empleador.

Aunque la expresión utilizada por la ley de entender una pluralidad de indicios, lo cierto es que eso obviamente no excluye que se considere un indicio como suficiente, cuando su calidad y precisión probatoria lo amerite. Por suficientes, expresión utilizada por la ley, debe entenderse, más que un número determinado de indicios, la exigencia de una cierta calidad de los mismos: deben permitir la sospecha razonable para el juez de que la vulneración se ha producido ${ }^{15}$. Así, el hecho de que empleador

inferencia del mismo tipo que la que define la prueba indirecta. Por tanto, desde el punto de vista del razonamiento no hay ninguna distinción esencial entre la llamada prueba directa y la indirecta, pues en ambos casos están presentes inferencias de la misma clase (inductivas, en concreto) y, en consecuencia, tan "teñida de subjetividad" puede estar la primera como la segunda. La idea de que la prueba directa es la que menos puede conducir a error judicial hay que ponerla en cuarentena”. GASCÓN, Marina, cit. (n.6) p. 89.

${ }^{14}$ Sentencia del Tribunal Constitucional español No 90/1997.

${ }^{15} \mathrm{La}$ calidad de un indicio está dada por su univocidad o precisión: si conduce necesariamente a generar la sospecha en el juez de que la vulneración se ha producido, porque no hay otra explicación alternativa más plausible, entonces, es suficiente. La pluralidad de indicios viene explicada porque "el procedimiento indiciario es inductivo, por lo que su resultado es de mera probabilidad, de manera que cuanto más indicios apoyen ese resultado más fiable será. Con todo, nada excluye, en principio, que un cierto hecho pueda ser probado a partir de un solo indicio si su calidad epistemológica, y, por tanto, su valor probatorio, es muy elevada". GASCÓN, Marina, cit. (n. 6), p. 156. 
despida a los trabajadores al otro día de terminarse el fuero laboral post negociación colectiva, lesionando la libertad sindical del afectado, o al día siguiente de ser notificado de una denuncia a la Inspección del Trabajo o una demanda judicial, lesionando su garantía de indemnidad, es solo un indicio, pero suficiente de que razonablemente se ha producido la conducta denunciada.

Frente a la aportación de los indicios suficientes, el empleador tiene la opción, como señala el mismo artículo 493 C.Trab., de explicar los fundamentos de las medidas adoptadas y de su proporcionalidad. El empleador debe aportar la prueba que acredite que la conducta denunciada obedece a motivos razonables y que la misma no dice relación con la vulneración de derechos fundamentales del trabajador.

Una rigurosa inversión de la carga formal de la prueba en esta materia podría someter al empleador "ante la prueba diabólica de un hecho negativo, como es la inexistencia de un móvil lesivo de derechos fundamentales, sino que ha de comprobarse la existencia de indicios de que se ha producido una violación de un derecho de tal naturaleza"16.

En rigor, el objeto de la prueba del empleador no es, como podría pensarse a primera vista, acreditar que su conducta no tenía como dirección la lesión de los derechos fundamentales del trabajador-lo que importaría, como ha señalado la jurisprudencia comparada, la prueba diabólica de un hecho negativo- ${ }^{17}$ sino que una cosa distinta: debe aportar elementos de prueba que le permitan justificar ante el juez laboral que su conducta obedece a motivos razonables, destruyendo de paso la sospecha que sobre ella recae ${ }^{18}$.

${ }^{16}$ Sentencia del Tribunal Constitucional español No 266/1993.

${ }^{17}$ Como lo ha señalado la jurisprudencia del Tribunal Constitucional español: "no se trata de situar al empresario ante la prueba diabólica de un hecho negativo (la no discriminación o la no lesión de cualquier otro derecho fundamental) pero si de entender que el despido, tachado de haber incurrido en aquella discriminación o en esta lesión, obedece a motivos razonables, extraños a todo propósito atentatorio contra el derecho fundamental en cuestión" (Sentencia del Tribunal Constitucional Español No 21/1992).

${ }^{18}$ En un reciente fallo del Tribunal Constitucional español se aprecia el modus operandi de la prueba indiciaria: el 30 de julio de 2002, la empresa Alitalia despidió a un trabajador que se desempeñaba como analista de marketing y con contrato de trabajo indefinido, según el aviso de despido por su indisciplina en el desempeño de su puesto de trabajo, la crítica constante a sus superiores y la desidia con que realiza su trabajo. El afectado demandó la nulidad del despido disciplinario del que fue objeto porque obedecía a razones discriminatorias por su condición de homosexual, dando el tribunal por acreditado como indicios de dicha conducta lesiva: i) que sus superiores conocían su tendencia sexual; ii) que existía un trato verbal despectivo del delegado de la empresa hacia ese colectivo; y iii) una deliberada sobrecarga de trabajo 


\section{LA PRUEBA Y EL DESPIDO LESIVO DE DERECHOS FUNDAMENTALES}

Una de las principales hipótesis de lesión de derechos fundamentales corresponde a la conducta que vulnere dichas garantías del trabajador con ocasión del despido, cuestión que, entonces, nos coloca dentro de la hipótesis de una nueva categoría del despido que se ubica entre el injustificado y el despido nulo, y cuya consecuencia es un recargo indemnizatorio previsto expresamente por la ley.

Aquí opera plenamente la regla del artículo 493 C.Trab. ya analizada y por tanto, al trabajador le corresponde, salvo que tenga prueba directa disponible, acreditar indicios suficientes de que el motivo del despido ha sido la lesión de sus derechos fundamentales inespecíficos.

Ahora, como el despido en Chile está sujeto a un sistema de causalidad prevista en la ley entre los artículos 159 y 161 C.Trab., es altamente probable que dicha conducta -el despido- esté aparentemente cubierto por una causal que lo justifique, cuestión que nos lleva directamente a la pregunta: ¿puede justificar el empleador la proporcionalidad del despido simplemente acreditando la efectividad de la causal legal de término respectiva?

Dicho de otro modo: puede el empleador, ante los indicios presentados por el trabajador, destruir la sospecha razonable de que se trata de un despido lesivo de derechos fundamentales acreditando la efectividad de la causal legal de término del contrato.

En rigor, desde el punto de vista conceptual, nada impide que el empleador haya tenido efectivamente una causal legal para poner término al contrato de trabajo, y al mismo tiempo, lesione con esa conducta los derechos fundamentales del trabajador. En palabras simples, es perfectamente posible que el empleador teniendo efectivas necesidades de la empresa haya decidido utilizar esa justificación para despedir, precisamente, al trabajador que efectuó un reclamo en la Inspección del Trabajo (garantía de indemnidad), o al que hizo declaraciones públicas sobre la empresa (libertad de expresión), o al que es homosexual (discriminación), etc.

Eso es lo que en la doctrina se denomina despido pluricausal, esto es, aquella hipótesis en que el empleador frente al panorama indiciario de lesión de derechos fundamentales aportado por el trabajador, logra acreditar

que le perjudicaba. Frente a estos indicios, la empresa no acreditó los incumplimientos laborales, sino se limitó a imputar generalidades, por lo que no justificó objetiva y razonablemente su conducta. De ese modo, el Tribunal Constitucional consideró acreditada la conducta lesiva de derechos fundamentales y declaró la nulidad del despido disciplinario señalado, ordenando el reintegro del trabajador respectivo (Sentencia del Tribunal Constitucional español No 41/2006). 
la existencia de una causal legal de término del contrato de trabajo. No se trata, en rigor, que el empleador alegue una causal de término ficticia o que no está en condiciones de probar, en cuyo caso se trataría de un despido de causalidad única y lesiva de derechos fundamentales, sino una cuestión distinta: el empleador está en condiciones de justificar su conducta lesiva en una causal de término plenamente acreditada.

En estos casos, concurren en el mismo despido dos causas que se mueven en planos distintos: una causa legal que justifica el despido del trabajador desde el punto de vista de las normas previstas para la terminación en el Código del Trabajo, y una causa anticonstitucional, consistente en la afección y lesión de un derecho fundamental del trabajador desde el punto de vista de las normas de tutela laboral.

En ese sentido, es perfectamente posible que dentro del procedimiento de tutela el empleador acredite la causal legal de término del contrato de trabajo respectivo, pero no esté en condiciones de justificar la no lesividad o la proporcionalidad del despido en términos de derechos fundamentales. En dicho caso, la conducta del despido ha efectivamente lesionado las garantías del trabajador, y por tanto, las consecuencias jurídicas del mismo serán las previstas en las nuevas normas de tutela. El despido pluricausal es, a fin de cuentas, un despido lesivo de derechos fundamentales ${ }^{19}$.

Ahora, como en el caso chileno la ley procesal laboral ha combinado al interior del procedimiento de tutela, en calidad de subsidiaria, la acción de despido injustificado, se han establecido dos objetos probatorios distintos dentro del mismo procedimiento. En efecto, como la prueba del procedimiento de tutela combinará usualmente ambas acciones, la de tutela como principal y la de despido injustificado como subsidiaria, entonces la prueba del empleador tendrá dos objetos distintos: en primer lugar, destruir el panorama indiciario del trabajador mediante prueba que acredite que tuvo una justificación razonable y no lesiva de derechos fundamentales, y al mismo tiempo, prueba que acredite que tuvo una causa legal para despedir.

$\mathrm{Y}$ en ese escenario es posible que sólo tenga éxito en una de ambas. Y puestos en ese punto, es perfectamente posible que se den 2 situaciones

${ }^{19}$ En ese sentido, precisamente, ha resuelto el Tribunal Constitucional español el problema del despido pluricausal, STC No 138/2006, sosteniendo que "en estos supuestos disciplinarios podrá neutralizarse el panorama indiciario, en primer lugar, acreditando de manera plena la causa legal expresada en la carta de despido, siempre que ese resultado probatorio revele efectivamente la desvinculación entre el acto empresarial y el derecho fundamental invocado (pues, como se sabe, la declaración de procedencia del despido no permite descartar -en todo caso y sin excepción-que éste sea lesivo de derechos fundamentales: por todas, STC 14/2002, de 28 de enero, FJ 7)". 
distintas: primero, que el empleador logre con su prueba destruir los indicios presentados por el trabajador, sorteando exitosamente la acción de tutela, pero no logre dar cuenta de la causal de término del contrato de trabajo, siendo condenado por despido injustificado (despido injustificado no lesivo). Y segundo, que el empleador acredite la existencia de una causal legal de término del contrato, pero no logre destruir el panorama indiciario presentado por el trabajador (despido pluricausal).

[Recibido el 3 de abril y aceptado el 21 de septiembre de 2009].

\section{BIBLIOGRAFÍA}

BAYLOS, Antonio, La igualdad de las partes en el proceso laboral y la tutela judicial efectiva, en Revista del Colegio de Abogados de Concepción 5 (1998).

CAAMAÑo, Eduardo, La defensa del principio de no discriminación por razones de sexo en el periodo anterior al nacimiento de la relación laboral, en Revista Laboral Chilena 116 (2003).

FraGA, Enrique Juanes, La prueba en el proceso de trabajo: novedades de la ley de Enjuiciamiento Civil, en VV. AA., El proceso laboral (Valladolid, Lex Nova, 2001)

GAMONAL, Sergio, El procedimiento de tutela de derechos laborales (2a edición, Santiago, LegalPublishing, 2008).

Garcia-Perrote, Ignacio, La prueba en el proceso de trabajo (1a edición, Madrid, Civitas, 1994).

Garcia-Perrote, Ignacio, Prueba y proceso laboral, en Derecho Privado y Constitución 4 (1994).

Gascón, Marina, Los hechos en el Derecho (1 ${ }^{a}$ edición, Madrid, Marcial Pons, 1999).

GiL, Juan, La carga de la prueba en el proceso laboral tras la LECiv 1/2000, en Revista Española de Derecho del Trabajo 126 (2005).

LOUSADA, José Fernando, La jurisprudencia constitucional sobre la prueba de la discriminación, en Revista de Derecho Social 30 (2005).

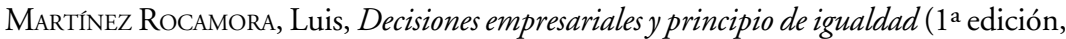
Barcelona, Cedecs, 1998).

Monereo, José Luis, La carga de la prueba en los despidos lesivos de derechos fundamentales ( $1^{\text {a }}$ edición, Valencia, Tirant lo Blanch, 1996).

SÁnCHEZ-Urán, Yolanda, Despido y móvil discriminatorio, en Actualidad Laboral 14 (2007).

Ugarte, José Luis, El Nuevo Derecho del Trabajo (1a edición, Santiago, Editorial Universitaria, 2004). 